\section{Genome deal seeks to} accelerate pore sequencing

Biotechnology company Illumina of San Diego, California, has bought exclusive rights to market, sell and distribute products based on the DNA sequencing technology of UK-based Oxford Nanopore Technologies (see Nature 456, 23-25; 2008).

Unlike conventional methods, the technique identifies sequences by passing DNA one base at a time through a tiny pore made from a protein. The process does not involve molecular tagging or intricate sample preparation, and the companies hope that it will ultimately allow them to sequence an entire human genome for less than US\$1,000.

The deal includes an initial investment of \$18 million from Illumina, followed by a second cash injection once Oxford Nanopore has demonstrated the commercial scope of the technique. Both firms will share profits from any sales.

\section{Obama urged to make exports and visas a priority}

The US National Research Council (NRC) has called on president-elect Barack Obama to overhaul the country's export-control system and to ease the visa process for foreign scientists.

In a report published on 8 January, the council warns that US security and economic growth are threatened by outdated export-control regulations, which restrict the flow of certain technologies and information to other countries. Rather than leaving items on the export-control list indefinitely, the NRC wants to see a 'sunset' rule imposed to reassess each item annually.

The report was co-chaired by former US national security adviser Brent Scowcroft and John Hennessy, president of Stanford University in California. It also suggests that Obama should speed up the processing of

\title{
Scheduling problems beset delayed Mars mission
}

NASA's delayed Mars Science Laboratory mission (pictured) is experiencing further problems as it jostles for space in a crowded launch schedule.

The nuclear-powered rover, which will search for evidence of past life on Mars, is due to launch at the end of 2011, two years later than planned.

But the mission's first possible launch window, in October, would be

tightly constrained by the August 2011 launch of Juno, a mission to study Jupiter's magnetic and gravitational fields. A second launch window is available in December, but that would favour landing sites in Mars's northern hemisphere, potentially reopening the debate over what part of the planet the rover should explore. Resolving the dilemma could add US $\$ 50$ million to the already vastly over-budget mission, now expected to cost up to $\$ 2.3$ billion over its lifetime. For a longer version of this story, see http://tinyurl.com/9j3ptj. 